\title{
Active pressure management through brine production for basin-wide deployment of geologic carbon sequestration
}

\author{
Karl W. Bandilla*, Michael A. Celia \\ Princeton University, Department of Civil and Environmental Engineering, Princeton, NJ, United States
}

\section{A R T I C L E I N F O}

\section{Article history:}

Received 12 October 2016

Received in revised form 8 March 2017

Accepted 22 March 2017

Available online 19 April 2017

\section{Keywords:}

Geologic carbon storage

Basin-scale modeling

Active pressure management

Area of review

Illinois Basin

\begin{abstract}
A B S T R A C T
In order for carbon capture and storage (CCS) to have a significant impact on anthropogenic carbon emissions, large volumes of carbon dioxide $\left(\mathrm{CO}_{2}\right)$ will need to be captured and stored in the subsurface. It is therefore likely that multiple storage operations will access the same storage reservoir, leading to the potential for overlapping pressure responses. Pressure management through brine production is an approach to reduce the pressure response of injection operations, concomitantly reducing the potential for overlap. In this study numerical modeling is used to simulate the basin-wide deployment of CCS in the Illinois Basin, USA to determine the potential impact of brine production on pressure increase at the injection wells and the Areas of Review (the area that the US Environmental Protection agency deems at risk for $\mathrm{CO}_{2}$ and brine leakage; AoR) of the injection operations. The results show that brine production can reduce the combined size of AoRs by about one order of magnitude, if a volume of brine equivalent to the volume of injected $\mathrm{CO}_{2}$ is produced. Sites with low injection rates and/or favorable storage properties (i.e., high permeability and porosity, large thickness and depth) may not need pressure management, if the critical pressure is only exceeded within the $\mathrm{CO}_{2}$ plume. Injection of $\mathrm{CO}_{2}$ at locations with favorable storage properties leads to a combined AoR 30\% smaller than if the injection sites are co-located with large stationary sources. However, pipeline networks would need to be developed to transport $\mathrm{CO}_{2}$ from the sources to the injection sites. If the produced brine is to be disposed through reinjection into the subsurface, the reinjection formation needs to be hydraulically isolated from the storage formation, as to not negate the effect of pressure management. The results also show that injectivity does not seem to be a major issue in the Illinois Basin, with only four out of 54 hypothetical CCS sites exceeding the allowable pressure increase set to prevent injection-induced seismicity. Unfortunately, brine production is not an effective strategy to control the maximum pressure increase at the four sites, so that a reduction in injection rates is necessary. If the injections occur at locations more favorable for injection, pressures are well below the maximum allowable levels, while maintaining the same basin-wide injection rates.
\end{abstract}

(c) 2017 Elsevier Ltd. All rights reserved.

\section{Introduction}

Carbon capture and sequestration (CCS) is being proposed as an important part of strategies to reduce anthropogenic carbon emissions (e.g., Kintisch, 2015; Metz et al., 2005). Deep saline formations are being considered for geologic carbon storage (GCS) due to their high storage capacity, high injectivity and relative abundance (Metz et al., 2005; NETL, 2015). Risks associated with GCS involve the leakage of fluids (both supercritical $\mathrm{CO}_{2}$ and resident brine) from the injection formation as well as induced seismicity. Both of these depend directly on the spatial extent and magnitude of pressure

\footnotetext{
* Corresponding author.

E-mail address: bandilla@princeton.edu (K.W. Bandilla).
}

increase in the injection formation. The density of the injected $\mathrm{CO}_{2}$ is lower than that of the resident brine, usually on the order of $250-750 \mathrm{~kg} / \mathrm{m}^{3}$. This strong density difference leads to a strong buoyant drive for the $\mathrm{CO}_{2}$. Therefore, a competent caprock - overlying the storage formation - is necessary to stop $\mathrm{CO}_{2}$ from migrating vertically to shallow groundwater aquifers, where it could acidify potential sources of drinking water (termed Underground Sources of Drinking Water, USDW), or even to the atmosphere. The injection of $\mathrm{CO}_{2}$ displaces the resident brine laterally in the storage formation and possibly vertically through the caprock, although vertical fluxes are likely to involve very slow flow rates. Significant vertical migration of brine will only occur along concentrated leakage pathways through the caprock; these pathways can be natural (e.g., faults) or due to human activities (i.e., abandoned wells). Unlike $\mathrm{CO}_{2}$ which will migrate vertically along a concentrated leakage pathway due 
to buoyancy, brine requires a pressure drive for vertical migration. In order to reduce the risk of leakage, GCS sites need to be carefully characterized to find all potential leakage pathways. For instance, the US Environmental Protection Agency (US EPA) defines an Area of Review (AoR), in which a GCS operator has to conduct a detailed characterization of the subsurface and mitigate any potential leakage pathways (EPA, 2010). The size of the AoR is determined by overlapping the footprint of the $\mathrm{CO}_{2}$ plume and the area where the formation pressure exceeds the so-called critical pressure, defined as the pressure necessary to lift brine from the injection formation through an open borehole to an overlying USDW.

Aside from acting as the pressure-drive for brine leakage, a pressure increase in the injection formation may also cause induced seismicity (Rutqvist, 2012). Seismic events have the potential to fracture the injection formation and caprock, creating concentrated leakage pathways (Zoback and Gorelick, 2012). If the seismic events are strong enough to be felt at the surface, public acceptance of a GCS operation is likely to decrease and may even lead to the abandonment of a project (Deichmann and Giardini, 2009). It should however be noted, that no significant seismic events have been reported related to GCS operations, and that proper GCS site selection reduces the risk of induced seismicity (Oldenburg, 2012; Zhang et al., 2013). In order to reduce the risk of seismic events, regulators often limit the allowable injection-induced pressure increase based on pre-injection pressure in the injection formation or critical stress regime. This means that $\mathrm{CO}_{2}$ injection rates may be limited due to pressure constraints.

Because both the risk of brine leakage and the risk of induced seismicity are related to the injection-induced pressure increase in the injection formation, pressure management in the injection formation is a strategy to reduce both of those risks. Production of brine from the injection formation reduces the pressure in the vicinity of the injection well, thus allowing brine production wells to be used for pressure management of a GCS operation. Production wells need to be located close to the injection wells to maximize impact of the pressure reduction, but far enough away so that the $\mathrm{CO}_{2}$ plume does not reach the production wells over the lifetime of the project (Court et al., 2012a). The location of the production wells also depends on the primary purpose of pressure management. If the goal is to reduce the pressure at the injection well (Buscheck et al., 2011) or the size of the AoR, wells are placed close to the well (Bandilla et al., 2012a). On the other hand, if the goal is to limit the pressure increase at a fault - to reduce the risk of induced seismicity - then wells are likely to be placed close to the fault (Birkholzer et al., 2012). While most proposed brine production strategies consist of a set of wells - often arranged in an inverted five-spot pattern - that operate throughout the injection phase of a GCS operation, more elaborate schemes have been proposed where production wells are converted to monitoring wells or $\mathrm{CO}_{2}$ injection wells once $\mathrm{CO}_{2}$ breaks through (Buscheck et al., 2011) or where brine is produced from the injection well for a period before $\mathrm{CO}_{2}$ injection commences (Buscheck et al., 2016).

One of the main issues related to pressure management through brine production is utilization and/or disposal of the produced brine. For salinities of $80,000 \mathrm{mg} / \mathrm{L}$ and below the produced brine may be desalinated and used to offset the water demand of carbon capture or for other industrial processes (Bourcier et al., 2011; Court et al., 2011). At GCS sites with high enough geothermal gradients, energy for electricity generation, industrial processes or district heating may be extracted from the produced brine. Brine that is too saline for desalination and concentrated brines resulting from desalination need to be either disposed of at the surface or reinjected into the subsurface. When reinjecting into the storage formation or adjacent formations, reinjection locations need to be chosen carefully, so that the impact of brine reinjection does not negate the pressure reduction goals of pressure management (Bandilla et al., 2012a).

Currently, pressure management through brine production is scheduled to be deployed at the Gorgon Carbon Dioxide Injection Project in Australia (Cook, 2009). Brine is planned to be produced at a volumetric rate of between one third and one half of the injection rate divided among four production wells, with disposal through re-injection into an overlying depleted gas reservoir. While the Gorgon Project is currently the only GCS site to include pressure management, several studies have investigated various aspects of brine production at GCS sites, including increased injectivity and storage capacity (e.g., Buscheck et al., 2012; Lindeberg et al., 2009; Michael et al., 2013), protection of sensitive features such as faults (Birkholzer et al., 2012; Cihan et al., 2014), reduction of the Area of Review (Bandilla et al., 2012a), and geothermal heat extraction (e.g., Buscheck et al., 2014; Buscheck et al., 2013). It should be noted, that with the exception of the study by Lindeberg et al. (2009) of enhanced storage capacity through brine production in the Utsira Formation off the coast of Norway and the study by Michael et al. (2013) on $\mathrm{CO}_{2}$ injection into formations with reduced initial pressure due to hydrocarbon production, all studies have been conducted at the site scale (that is, an individual injection operation). However, a large number of GCS sites will be necessary for CCS to have a significant impact on anthropogenic carbon emissions. Pacala and Socolow (2004) estimate that $\mathrm{CO}_{2}$ from about 800 large coal-fired power plants would need to be captured and stored to achieve about one tenth of the emissions reduction necessary to limit the global temperature increase to $3^{\circ} \mathrm{C}$. It is therefore likely that multiple GCS operations will target the same storage formation, leading to the potential for interference among injection operations. For instance, studies of a hypothetical industrial-scale deployment of GSC operations in the Illinois Basin (USA) have shown that the expected pressure response from injection of $100-200 \mathrm{Mt} / \mathrm{yr}\left(\mathrm{Mt}=10^{12} \mathrm{~g}\right)$ of $\mathrm{CO}_{2}$ would extend throughout the basin (Bandilla et al., 2012b; Person et al., 2010; Zhou et al., 2010). It is therefore important to study the impact of pressure management at the basin scale.

The goal of the study presented here is to investigate the impact of pressure management through brine production at the basin scale to capture the interference among injection sites. First, the modeling approach and test case used for this study are discussed, followed by a description of how brine production for GCS sites is implemented in this study. Then, modeling results for different pressure management scenarios are presented and discussed. Finally, a set of conclusions is presented.

\section{Methods}

In order to assess the impact of active pressure management through brine production on geologic carbon storage, numerical models are used to predict the pressure response as well as the migration of the injected $\mathrm{CO}_{2}$ and the resident brine. GCS is modeled as a two-phase flow problem involving super-critical $\mathrm{CO}_{2}$ as the gas phase and brine as the liquid phase. Geomechanical effects, such as permeability enhancement through reactivation of existing fractures, are neglected in this study; however, the compressibility of the rock matrix is taken into account. The impact of geochemistry is neglected as well, because the alteration of flow properties due to precipitation of minerals or dissolution of the rock matrix are usually negligible (e.g., Johnson et al., 2005). Dissolution of $\mathrm{CO}_{2}$ into brine, and vice versa, is also neglected, as it is not expected to have a significant impact due to the relatively high salinity of the brine considered in this study. In addition to neglecting geochemistry and geomechanics, it is assumed that the vertical segregation of $\mathrm{CO}_{2}$ and brine occurs quickly, so that phase pressures can be assumed 
to be at equilibrium in the vertical direction; this assumption is usually termed the vertical equilibrium (VE) assumption. The VE assumption is likely valid for this study, due to the multi-decadal timeframe of the study and the relatively high permeability of the injection reservoir considered here. For a more detailed discussion on the applicability of the VE assumption, please refer to Yortsos et al. (1993), Nordbotten and Dahle (2011) and Court et al. (2012b).

In this study, a vertically-integrated modeling approach is used, due to the large spatial scale of basin-wide deployment of GCS. The reader is referred to Bandilla et al. (2015) for a more detailed presentation of available modeling approaches relevant to GCS. Based on the assumptions described above, a set of vertically-integrated governing equations can be derived, including mass balance equations for the two phases, volumetric flux equations (modified Darcy), constitutive equations describing the relationship between saturation, capillary pressure and relative permeability, and a closure equation that stipulates that the entire pore space is occupied by the two phases. In addition, reconstruction operators need to be defined to reconstruct vertical saturation and pressure profiles. Derivations of the vertically-integrated governing equations, along with descriptions of the constitutive equations and reconstruction operators can be found in Nordbotten and Celia (2012) and are thus not shown here.

Due to the spatial variability in reservoir properties (e.g., porosity, permeability, thickness), the governing equations need to be solved numerically. The domain is discretized into a horizontal (i.e., perpendicular to gravity) grid of two-dimensional rectangular cells, and the discretized governing equations are solved using an Implicit-Pressure-Explicit-Saturation (IMPES) approach. Each permeable formation in the sedimentary stack is represented by a two-dimensional grid and the grids are vertically coupled through diffuse leakage through low-permeability formations separating the high-permeability formations. Simulations are run using the vertically-integrated simulator VESA (Bandilla et al., 2012b), which allows spatially varying formation properties, multiple stacked formations, and the representation of a capillary transition zone. Injection and production wells are treated as sources and sinks in the grid cells with wells.

To reduce the computational intensity of this modeling study, the grid is not refined in the vicinity of the wells. Using coarse grid cells in the vicinity of wells has very little impact on the largescale pressure response which is important for delineating the GCS operations' AoR. However, a cell-average pressure value is not appropriate when calculating the pressure at the injection well. Therefore, the well pressures are reconstructed from the grid cell pressures using a semi-analytic multi-phase flow solution introduced by Nordbotten and Celia (2006).

The Illinois Basin in the Midwestern US is chosen as a test site to investigate the impact of an industrial-scale deployment of GCS in a sedimentary basin. The Illinois Basin is chosen for its high density of large stationary $\mathrm{CO}_{2}$ sources and large $\mathrm{CO}_{2}$ storage potential (NETL, 2015). The Illinois Basin underlies the states of Illinois and Indiana and consists of a thick sequence of sedimentary formations of sandstones, carbonates and mudstones. The Mount Simon Sandstone Formation lies at the bottom of the sedimentary stack on the Precambrian basement. Due to its large thickness and porosity, high permeability, a competent caprock (Eau Claire Formation) and sufficient depth, the Mount Simon Sandstone is considered the primary $\mathrm{CO}_{2}$ injection target in the Illinois Basin. Although there is currently only one active GCS operation in the Illinois Basin (Finley, 2014), several studies have been conducted to predict the pressure response as well as $\mathrm{CO}_{2}$ and brine migration for industrial-scale GCS operations (Bandilla et al., 2012b; Person et al., 2010; Zhou et al., 2010). The studies found that the Mount Simon Sandstone has sufficient injectivity and storage capacity for basin-wide injection rates ranging between 100 and $200 \mathrm{Mt} / \mathrm{yr}$ for between 30 and 50 years.
Table 1

Mean permeability and porosity values for the eleven model layers; from top to bottom of sedimentary stack.

\begin{tabular}{lll}
\hline Layer name & Mean permeability $[\mathrm{mD}]$ & Mean porosity $[-]$ \\
\hline Ordovician units & 106.0 & 0.12 \\
Upper Knox Group & 0.002 & 0.11 \\
Lower Knox Group & 46.7 & 0.11 \\
Eau Claire & 0.001 & 0.10 \\
Upper Mt Simon & 103.5 & 0.12 \\
Mt Simon layer \#5 & 5.2 & 0.09 \\
Mt Simon layer \#4 & 103.5 & 0.12 \\
Mt Simon layer \#3 & 5.2 & 0.10 \\
Mt Simon layer \#2 & 155.2 & 0.13 \\
Mt Simon layer \#1 & 5.2 & 0.13 \\
Mt Simon Arkosic Unit & 517.3 & 0.20 \\
\hline
\end{tabular}

They also found that the $\mathrm{CO}_{2}$ plumes could be attributed to specific injection wells, while the pressure responses from individual injection operations overlapped, causing a basin-wide pressure increase (Fig. 1).

The study presented here uses a spatially more refined version of the Illinois Basin model developed in Bandilla et al. (2012b). The model consists of six high permeability layers, separated by five low permeability layers. The bottom seven of the eleven layers represent the Mount Simon Sandstone; the eighth layer represents the Eau Claire Formation; the top-most layer (layer 11: Ordovician Units) is considered the deepest freshwater aquifer. The model covers an area of over $300,000 \mathrm{~km}^{2}$ and a thickness between 280 and $4260 \mathrm{~m}$. The topography of the Illinois Basin is roughly bowlshaped, with the greatest depth at the southern edge of the basin. Permeability, porosity and thickness of the layers vary spatially, with porosity and permeability correlated with depth through an Athy-type relationship (Athy, 1930; Person et al., 2010); mean porosity and permeability values for the eleven layers are given in Table 1. Each layer is discretized into over 108,000 cells, with $1.67 \mathrm{~km} \times 1.67 \mathrm{~km}$ cell sizes; the thickness of the cells varies spatially and depends on the topography of the layers. For a more detailed description of the Illinois Basin model the reader is referred to Bandilla et al. (2012b). It should be pointed out that only a few wells have been drilled into the deeper part of the Mount Simon Sandstone, so that the stratigraphy and rock parameters are somewhat uncertain in this part of the domain.

To model the impact of an industrial-scale deployment of CCS, it is assumed that all large stationary $\mathrm{CO}_{2}$ sources related to electricity production, ethanol production, and oil and gas processing add capture facilities that capture $100 \%$ of the otherwise emitted $\mathrm{CO}_{2}$. According to the US Department of Energy's NATCARB database 172 such sources with combined emissions of about $320 \mathrm{Mt} / \mathrm{yr}$ are located within the Illinois Basin (Bandilla et al., 2012b); this represents about $5 \%$ of total US $\mathrm{CO}_{2}$ emissions. At 72 of the 172 sources the Mount Simon Sandstone is either too shallow (northern part) or has too low injectivity (southern part) for GCS operations, leaving 100 emitters with combined emissions of approximately $207 \mathrm{Mt} / \mathrm{yr}$. Two injection scenarios are considered for this study: one where $\mathrm{CO}_{2}$ is injected at the site of the emitter (termed on-site) and one where $\mathrm{CO}_{2}$ is transported to the center of the basin for injection (termed regional center). Injection occurs in the lowest layer of the Mount Simon Sandstone, the Arkosic Unit, for both injection scenarios. See Fig. 2 for injection formation thickness. For the on-site scenario, emitters that are within a distance of $20 \mathrm{~km}$ of each other are combined into a single injection site at the location of the larger emitter. This leads to 54 injection sites, with injection rates ranging from 0.01 to $21.2 \mathrm{Mt} / \mathrm{yr}$ (average rate $3.8 \mathrm{Mt} / \mathrm{yr}$ ). For the regional center scenario, 42 injection sites are arranged in a $6 \times 7$ grid in the center of the basin, with a spacing of $15 \mathrm{~km}$ between sites. The location of the regional center is based on optimal reservoir properties (i.e., appropriate depth, high permeability and porosity). $\mathrm{CO}_{2}$ is 


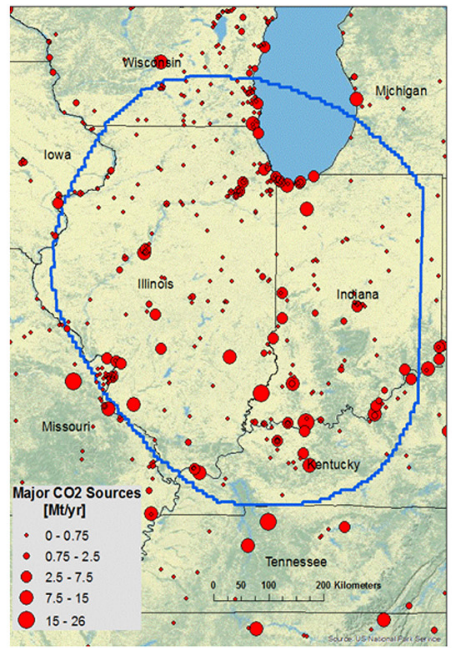

a) domain boundary and stationary $\mathrm{CO}_{2}$ sources
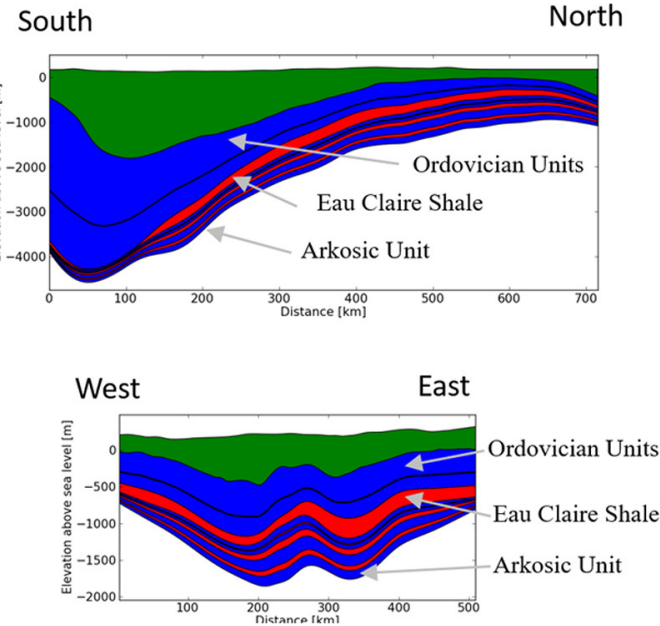

b) stratigraphy cross-sections

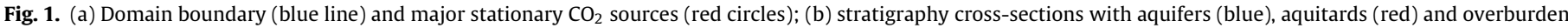

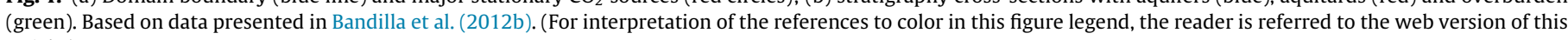
article.)

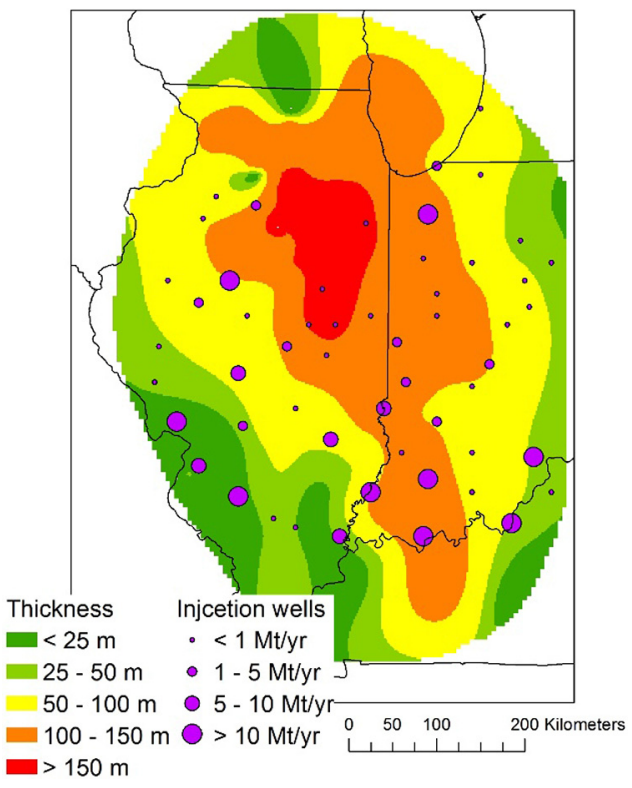

Fig. 2. Thickness of the injection formation (Arkosic Unit of the Mount Simon Sandstone) with locations and injection rates of $\mathrm{CO}_{2}$ injection wells in the on-site scenario.

injected for a duration of 50 years at constant injection rates, and all injection operations start at the same time (i.e., no staggered rollout). Due to the high injection rates at some of the sites, several vertical or horizontal injection wells may be necessary to reduce the injection pressure. However, in the model presented here, only a single vertical injection well is used, as the pressure response and fluid migration are similar for a single well and a closely spaced cluster of wells, when viewed at the resolution of interest in this study.

Four production wells are located around each injection in an inverted five-spot pattern, and brine is produced from the Arkosic Unit of the Mount Simon Sandstone. The distance between a brine production well and an injection well is inversely proportional to the beneficial impacts of the production well (i.e., reducing injection pressure and reducing the AoR). However, production wells need to be located far enough from injection wells to prevent the injected $\mathrm{CO}_{2}$ from reaching the production well. For the on-site scenario, the distance of the production wells to the injection wells is based on the $\mathrm{CO}_{2}$ plumes predicted for a case without production, but the distance is increased if $\mathrm{CO}_{2}$ reaches a production well; the production wells are located north, south, east and west directly outside of the individual plumes (Fig. 3). This configuration leads to 216 production wells for the on-site scenario. The locations of the production wells for the regional center scenario are in the cell centers of a grid with the injection wells as nodes, leading to 56 production wells $(7 \times 8$ pattern $)$.

The brine production rate is directly proportional to the beneficial impacts of the production well, but higher pumping rates lead to higher operating costs due to higher energy demand and increase the volume of produced brine that needs to be disposed of. Previous studies have suggested that producing the same volume of brine as the volume of $\mathrm{CO}_{2}$ that is injected leads to effective pressure control (Buscheck et al., 2011). For the on-site scenario, the four production wells surrounding an injection well each have the same production rate, typically one quarter of the $\mathrm{CO}_{2}$ volumetric injection rate. The production rates for the regional center wells depends on the location of the well relative to the injection wells: wells within the field produce the same volume as is injected per well, wells along the edges of the field produce half the volume, and wells at the corners of the field produce one quarter of the volume. The different production rates are based on overlapping production well locations within the field. The brine production rates are set to be constant over time, but are varied for different modeling runs, to investigate the impact of the produced volume on the pressure response.

Produced brine may be desalinated or used as heat exchange fluid in a geothermal operation, as described above. However, the brine in the Mount Simon Sandstone has very high salinity of up to $260,000 \mathrm{mg} / \mathrm{L}$ (Zhou et al., 2010), which is much higher than current desalinization technologies can handle (Bourcier et al., 2011). Also, the temperatures in the Mount Simon Sandstone are relatively low with a temperature gradient of $18.9^{\circ} \mathrm{C} / \mathrm{km}$ depth (Mehnert et al., 2014), not high enough for geothermal energy extraction. It is therefore likely, that produced brine will either be disposed of at the surface or reinjected into the subsurface. In this study surface disposal is considered as the base case, because surface disposal 


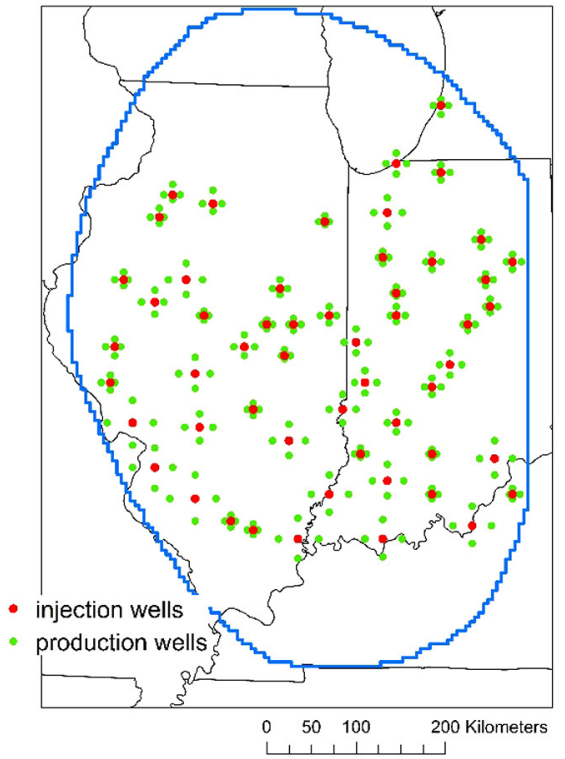

a) on-site scenario

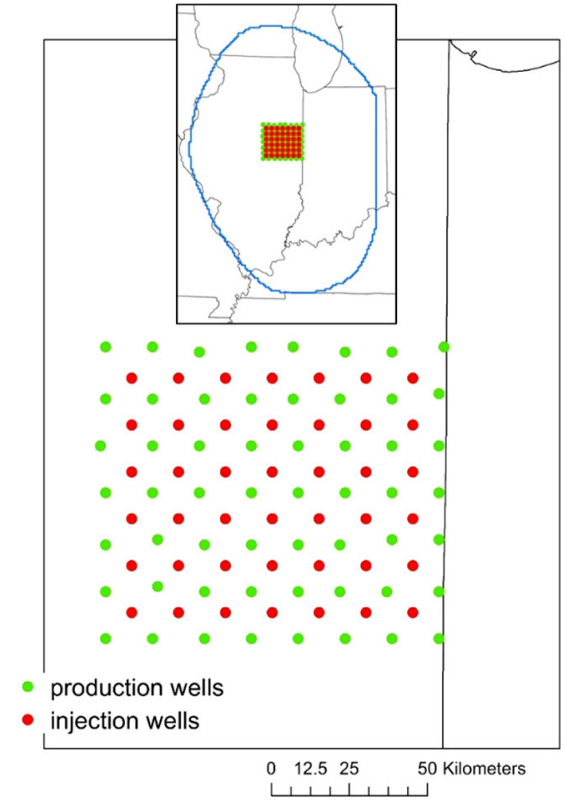

b) regional center scenario

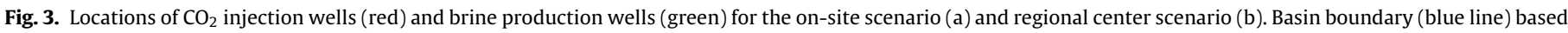
on data presented in Bandilla et al. (2012b). (For interpretation of the references to color in this figure legend, the reader is referred to the web version of this article.)

has no impact on the pressure response in the subsurface. Brine reinjection targets are both the uppermost layer of the Mount Simon Sandstone and permeable layers of the Knox Formation. The uppermost layer of the Mount Simon Sandstone is targeted because of its relatively high permeability, while the Knox formation is chosen because it lies above the primary caprock (Eau Claire) but still is relatively deep. For this study, the re-injection wells are located close to the brine production wells to reduce the transport of brine at the surface. The brine injection rates are varied for different modeling runs to simulate reduced re-injection volumes due to injection of concentrated brine from future desalinization technologies or partial surface disposal.

As mentioned above, pressure management has the effects of reducing the $\mathrm{CO}_{2}$ injection pressure and reducing the size of the AoR. Therefore, both exceedance of injection pressure limits and the areal extent of the AoR are used as metrics to compare different pressure management scenarios, in this study. The allowable pressure increase (often termed fracture pressure) is limited to $65 \%$ of the pre-injection pressure in the Illinois Basin (Zhou et al., 2010). The Mount Simon Sandstone is assumed to be at hydrostatic conditions, so that the pre-injection pressure is the hydrostatic pressure at the top of the Mount Simon Sandstone using a brine density of $1000 \mathrm{~kg} / \mathrm{m}^{3}$ as a conservative estimate. Fig. 4a shows the maximum allowable injection-induced pressure increase above pre-injection pressure.

As described above, the AoR is established by overlaying the predicted $\mathrm{CO}_{2}$ plume extent and the area where the critical pressure is exceeded. For this study, the critical pressure is calculated for each numerical grid cell (Bandilla et al., 2012c):

$P_{\text {crit }}=\frac{g l}{2}\left(\rho_{b}-\rho_{w}\right)$

where $P_{\text {crit }}$ is the critical pressure increase, $l$ is the vertical distance between the top of the injection aquifer and the bottom of the USDW, $\rho_{b}$ is the density of brine in the injection aquifer, $\rho_{w}$ is the density of the water in the USDW, and $g$ is gravitational acceleration. The Ordovician Units are considered the USDW in this study, so that $l$ is the vertical distance from the top of the Mount Simon
Arkosic Unit (the injection formation) to the bottom of the Ordovician Units. The salinity in the injection formation is estimated based on a salinity gradient of $65,000 \mathrm{mg} / \mathrm{L} / \mathrm{km}$, estimated from data in Michael et al. (2010) with a salinity of $0 \mathrm{mg} / \mathrm{L}$ at the surface; the temperature is estimated using a gradient of $18.9^{\circ} \mathrm{C} / \mathrm{km}$ with a surface temperature of $10^{\circ} \mathrm{C}$. Due to a lack of detailed salinity data for the Ordovician Units, the salinity in the USDW is assumed to be $10,000 \mathrm{mg} / \mathrm{L}$ which is the threshold below which the US EPA considers an aquifer to be a USDW. Assuming a lower salinity in the Ordovician Units would lead to a higher critical pressure and would therefore be a less conservative estimate. The densities of the brine in the injection formation and water in the USDW are computed based on Battistelli et al. (1997). Based on Eq. (1) the estimated critical pressure ranges from $0.1 \mathrm{MPa}$ in the shallow northern part of the Illinois Basin to over $1 \mathrm{MPa}$ in the deep southern section (Fig. 4b). The critical pressure closely tracks the depth of the injection formation, as distance to the USDW and density increase with depth. Both salinity and temperature increase with depth, but over the range of interest here, the impact of salinity on brine density is stronger than that of temperature (Bandilla et al., 2012c), leading to an overall increase of brine density with depth. As a post-processing step, the predicted pressure increase is compared to the critical pressure on a cell-by-cell basis to determine the area where the critical pressure is exceeded. The AoRs are then defined by cells where either the critical pressure is exceeded or the $\mathrm{CO}_{2}$ saturation is greater than $0.1 \%$.

As noted above, the AoR is a combination of the pressure response and $\mathrm{CO}_{2}$ plume footprint. If the goal of a pressure management operation is to minimize the AoR, then the smallest possible AoR is the $\mathrm{CO}_{2}$ footprint. The ratio of the area of the AoR to the area of the $\mathrm{CO}_{2}$ plume, termed the AoR-plume ratio here, is therefore used as a performance metric in this study. A high AoR-plume ratio indicates that the AoR is mainly defined by the pressure response, while a ratio close to one points to an AoR where the critical pressure is exceeded only in a small area outside of the $\mathrm{CO}_{2}$ plume. A high AoR-plume ratio also suggests a high potential for reduction of the size of the AoR through pressure management. 


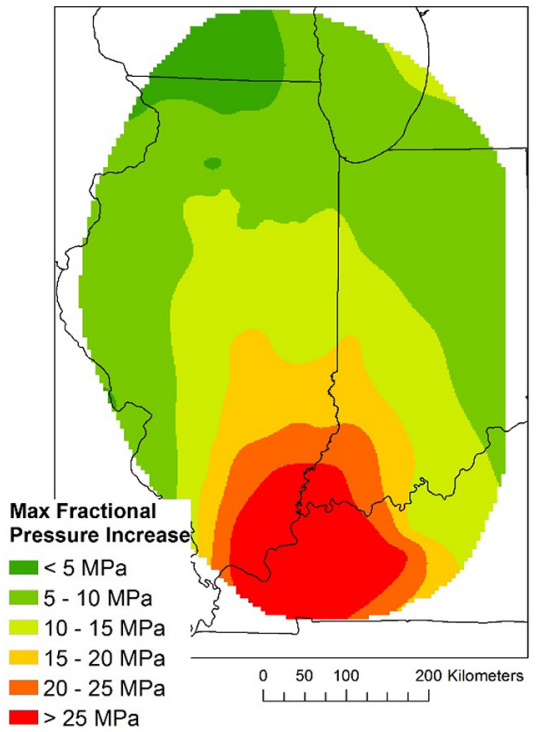

a) maximum allowable pressure increase

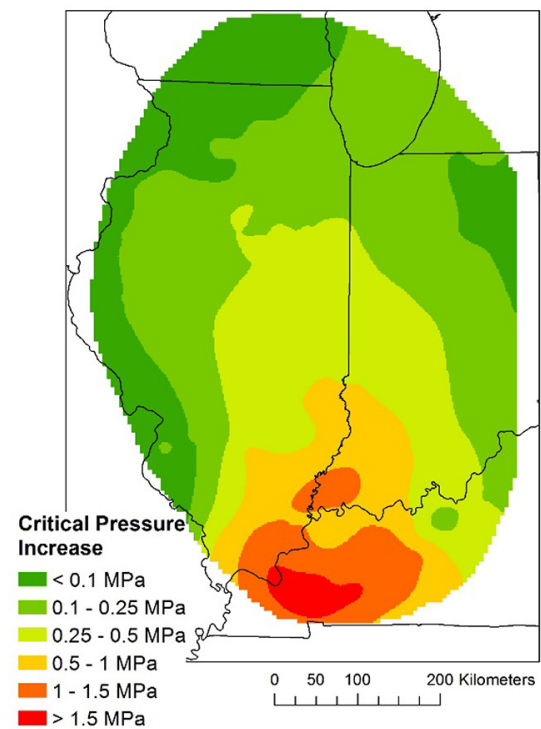

b) critical pressure increase

Fig. 4. Basin-wide distribution of: (a) maximum allowable pressure increase, and (b) critical pressure increase for AoR delineation (increase above hydrostatic pressure).

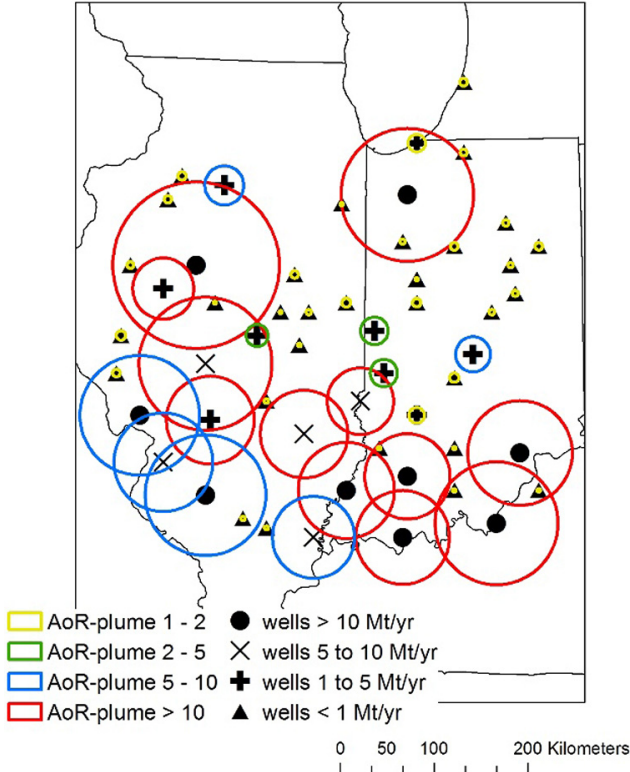

Fig. 5. AoRs extents and AoR-plume ratios based on individual sites for the on-site scenario after 50 years of continuous $\mathrm{CO}_{2}$ injection.

\section{Results}

\subsection{On-site scenario}

Using the Illinois Basin model described above, simulations are run for 50 years to investigate the role of active pressure management through brine production in a hypothetical industrial-scale deployment of GCS. In an initial step, the impact of each of the 54 injection sites is modeled separately by running models where only a single site is active. Fig. 5 shows that the individual AoRs can be very large, with the diameters of area-equivalent circles reaching up to $180 \mathrm{~km}$, and that overlap of neighboring AoRs should be expected, especially for larger injection sites. However, at 31 of the 54 sites the AoR is quite small and is completely defined by the $\mathrm{CO}_{2}$ plume footprint (i.e., an AoR-plume ratio of one). The injection rates at these sites is small (less than $1 \mathrm{Mt} / \mathrm{yr}$ ), and the AoR-plume ratio increases as the injection rate increases. The largest individual AoRs are characterized by very large AoR-plume ratios, leading to the expectation that the AoR sizes may be significantly reduced by pressure management.

The on-site injection scenario with simultaneous injection at all sites for 50 years without brine production is presented as a base cases. The predicted $\mathrm{CO}_{2}$ plumes are close to radial and remain local to the injection sites, with little migration due to caprock topography and no overlap of neighboring plumes (Fig. $6 \mathrm{a}$ ). $\mathrm{CO}_{2}$ plume diameters range from about $3 \mathrm{~km}$ to about $42 \mathrm{~km}$. It should be noted that the saturation values reported here are average values over a grid cell, which means that saturations close to the injectors can be expected to be higher than the values shown in Fig. 6a, especially for sites with low injection rates. The largest plumes are in the southwestern part of the domain. The sizes of the three largest plumes can be explained by a combination of high injection rate $(7.7,11.5$ and $12.7 \mathrm{Mt} / \mathrm{yr})$ and low thickness of the injection formation $(12,12$ and $16 \mathrm{~m}$ ). Unlike the $\mathrm{CO}_{2}$ plumes, the pressure response is basinwide, with a pressure increase greater than $0.25 \mathrm{MPa}$ throughout a large part of the domain (Fig. 6b). The strongest pressure response is in the southern part of domain, and is due to low permeability in the deepest part of the domain and to a clustering of sites with high injection rates. Interestingly, the strongest pressure increase does not coincide with the highest injection rate. This can be explained by lower permeability and the proximity to an abrupt permeability decrease at southern tip of the domain. Also, the area of strongest pressure response does not coincide with the area of largest $\mathrm{CO}_{2}$ plumes, as high permeability leads to large plumes and low pressures.

Fractional pressure increases (pressure increase at injection well divided by pre-injection pressure) exceed the maximum allowed value of 0.65 at four of 54 injection sites, with fractional pressure increases ranging from 0.7 to 1.2 . The four sites are located along the southwestern edge of the domain; the four southwestern sites with blue circles in Fig. 5 . The formation thickness at the four sites is low at $16.3,12.1,11.9$ and $29.3 \mathrm{~m}$ while the injection rates are high 11.5 7.7, 12.7 and $7.3 \mathrm{Mt} / \mathrm{yr}$. The combination of high injection rate and low thickness leads to high injection pressures. Therefore, injection rates at the four sites would be limited due to too high injection pressures. In order to not exceed the fractional pressure increase 


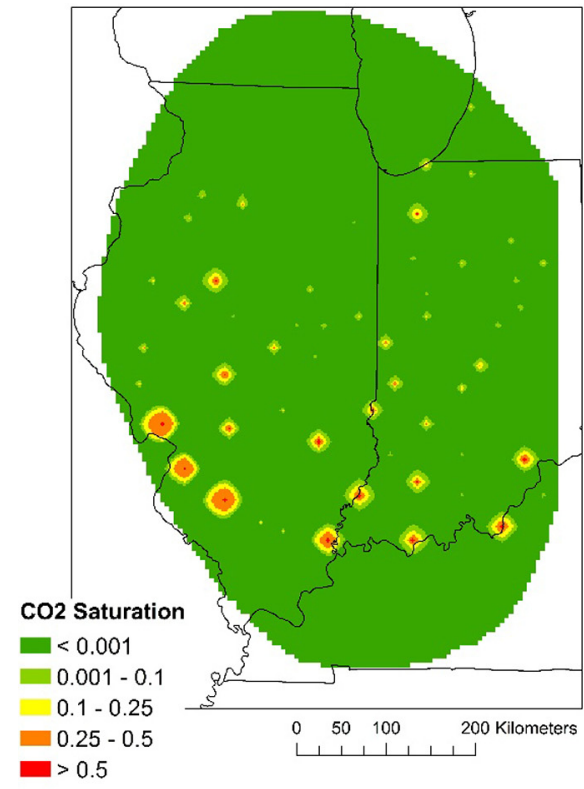

a) $\mathrm{CO}_{2}$ saturation

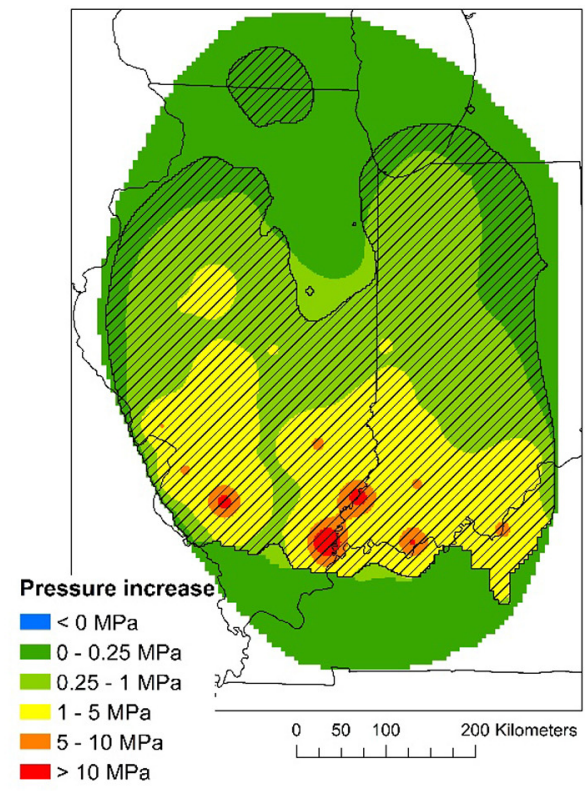

b) pressure increase and AoR

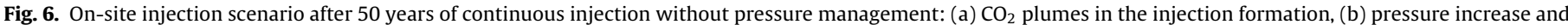
AoR (hatched area) in the injection formation.

limit of 0.65 , the injection rates at the four sites need to be reduced by between 25 and $50 \%$; a combined reduction of $18.6 \mathrm{Mt} / \mathrm{yr}$, or about $9 \%$ of the full injection rate of $207 \mathrm{Mt} / \mathrm{yr}$.

The predicted combined AoR covers approximately $198,000 \mathrm{~km}^{2}$, or $65 \%$ of the entire basin. Such a large AoR means that storage operators would have to characterize the subsurface of most of Illinois and Indiana and investigate, and possibly mitigate, any concentrated leakage pathways such as abandoned wells or faults. In addition, AoRs of individual injection operations are overlapping with other AoRs, making it difficult to apportion a specific AoR to an injection operation. Only about $12,500 \mathrm{~km}^{2}$ of the combined AoR is defined by the presence of $\mathrm{CO}_{2}$ (an AoR-plume ratio of 15.8); in other words pressure management has the potential to reduce the AoR by a factor of about 16 .

Production of brine from the injection formation significantly reduces the AoR, as intended. For the case where the same volume of brine is extracted as the volume of $\mathrm{CO}_{2}$ that is being injected (termed volume-equivalent production from here on), the AoR for the on-site scenario is reduced to $18,000 \mathrm{~km}^{2}$ (Fig. 7); a reduction by a factor 11 . The AoRs of two sites in the southwest of the basin are still connected, leading to an ambiguity about which injection operator is responsible for characterization and mitigation. However, a more strategic placement of the production wells would likely separate the two AoRs. Unlike the scenario without production where all AoRs were defined by exceeding the critical pressure, the AoRs of only 14 of the 54 sites is defined by the pressure, with an overall AoR-plume ratio of 1.4. Brine production also leads to an area of $140,000 \mathrm{~km}^{2}$ where pressure is below the initial pressure. While this under pressure eliminates the risk from vertical and horizontal brine migration by creating regional pressure gradients toward the GCS sites, this large area suggests that too much brine is being produced. A total of $277,000,000 \mathrm{~m}^{3} / \mathrm{yr}-$ or $759,000 \mathrm{~m}^{3} /$ day - are produced under this production scenario.

The pressure reduction through volume equivalent brine production reduces the fractional pressure increase at only one of the four site below the maximum allowable value. Doubling the brine production rates at the three remaining sites with too high pressure, sufficiently reduces the pressure increase at one more

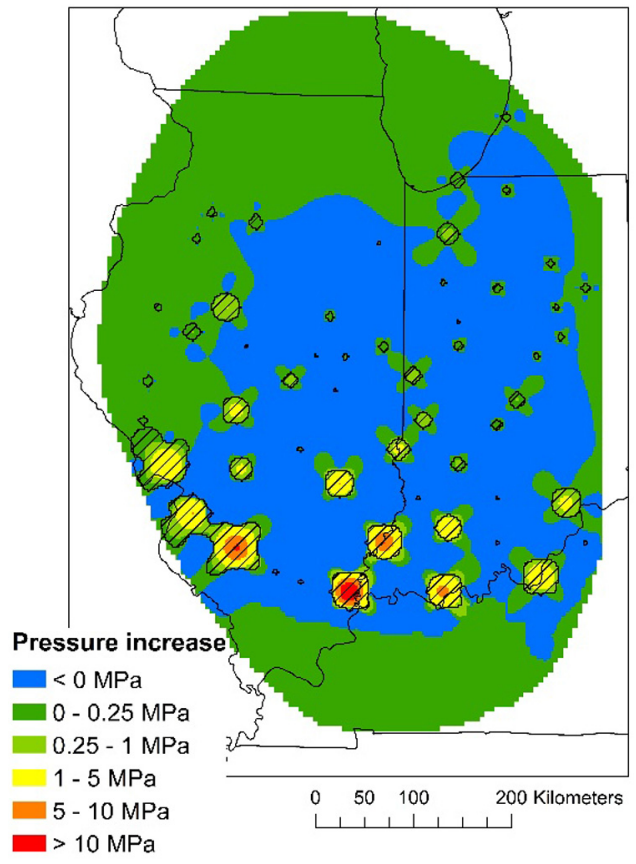

Fig. 7. Pressure increase and AoR in the injection formation for the on-site scenario after 50 years of continuous injection with $100 \%$ brine production. The blue area indicates that pressure is lower than pre-injection pressure. (For interpretation of the references to color in this figure legend, the reader is referred to the web version of this article.)

injection well, but at the cost of $\mathrm{CO}_{2}$ breakthrough at the brine production wells and increased volumes of brine that need to be treated or disposed.

Two obvious strategies to reduce the volume of produced brine are: reduce the ratio of brine produced to $\mathrm{CO}_{2}$ injected, and reduce the number of sites where brine is produced. Both of these strategies are investigated in this study, with overall brine production reduced to 75,50 and $25 \%$ of the volume-equivalent production, 
Table 2

AoRs for reduced brine production rates. The percentage values in the second column are AoR size relative to the case of no brine production.

\begin{tabular}{lll}
\hline Scenario & Combined AoR $\left[1000 \mathrm{~km}^{2}\right]$ & AoR-plume ratio \\
\hline No brine production & $198.1(100 \%)$ & 15.85 \\
$25 \%$ brine production & $174.9(88.3 \%)$ & 13.96 \\
$50 \%$ brine production & $126.5(63.8 \%)$ & 10.05 \\
$75 \%$ brine production & $57.7(29.1 \%)$ & 4.56 \\
$100 \%$ brine production & $17.9(9.0 \%)$ & 1.41 \\
\hline
\end{tabular}

and sites chosen based on their AoR-plume ratio. The number of sites is reduced in four steps: sites with an AoR-plume ratio of one (i.e., the AoR is entirely defined the $\mathrm{CO}_{2}$ plume), and sites where the AoR is two, five and ten times larger than the $\mathrm{CO}_{2}$ plume size (AoR-plume ratios of 2,5 , and 10, respectively). Reduction of brine production rates by $25 \%$ increases the total AoR to about $58,000 \mathrm{~km}^{2}$; an increase by a factor of around 3 compared to the case of $100 \%$ brine production. The increase in AoR size leads to a merging of individual AoRs, resulting in three clustered AoRs in the southern half of the basin containing most of the large sources. In addition, an AoR not associated with a GCS site appears in the northern part of the basin. The pressure response from injection operations tens of kilometers away is sufficient to exceed the critical pressure in this area, due to the relatively short separation distance between the storage formation and the lowest USDW. Further reduction of the brine production rates exacerbates the problems of a growing total AoR and merging individual AoRs, with the total AoR growing to 126,000 and $175,000 \mathrm{~km}^{2}$ for 50 and $25 \%$ of brine production rates, respectively. Table 2 shows details of the AoRs for reduced brine production.

In an attempt to better target pressure management at GCS sites with large AoRs, the number of GCS sites with brine production is reduced based on the AoR-plume ratios of individual sites. At the 31 GCS sites with AoR-plume ratios of one pressure management is not going to be able to reduce the size of the AoR, as the AoR is defined by the $\mathrm{CO}_{2}$ plume only. Removing the 124 brine production wells associated with the 31 GCS sites has very little impact on the total AoR, increasing the total AoR by about $300 \mathrm{~km}^{2}$ compared to the case with pressure management at every site (Fig. 8). The small increase is mainly due to the AoR of a smaller GCS site, where no pressure management is being conducted, merging with a larger one on the southwestern edge of the basin. This is the only location where combined pressure responses from a site without pressure management and a site with pressure management is sufficient to exceed the critical pressure outside of the $\mathrm{CO}_{2}$ plume. While the number of production wells is greatly reduced in this scenario, the basin-wide volume of brine produced only decreases by $0.33 \mathrm{~m}^{3} / \mathrm{s}$, or about $4 \%$, compared to the scenario where brine is produced at every GCS site. This relatively small decrease is because all the sites where pressure management was disbanded have $\mathrm{CO}_{2}$ injection rates less than $1 \mathrm{Mt} / \mathrm{yr}$. Further reducing the number of GCS sites with pressure management by eliminating all sites where the AoR is up to twice as big as the $\mathrm{CO}_{2}$ plume footprint (i.e., an AoR-plume ratio of 2), leaves a total of 20 sites with pressure management. In this scenario the total AoR grows by an additional $1200 \mathrm{~km}^{2}$, but there are no additional site mergers. However, an AoR not directly associated with any GCS site appears again in the northern part of the basin. The basin-wide brine production rate is reduced by about $7.5 \%$ compared to the scenario where pressure management is conducted at every site. Removing pressure management at all sites where the AoR is five times larger (AoR-plume ratio of 5) and ten times larger (AoR-plume ratio of 10) than the $\mathrm{CO}_{2}$ plume footprint leaves 17 and 10 sites with pressure management, respectively. While removing more sites leads to a larger decrease in brine production rates (14 and 52\% reduction compared to production at all sites), the reduced pressure management allows additional AoRs to

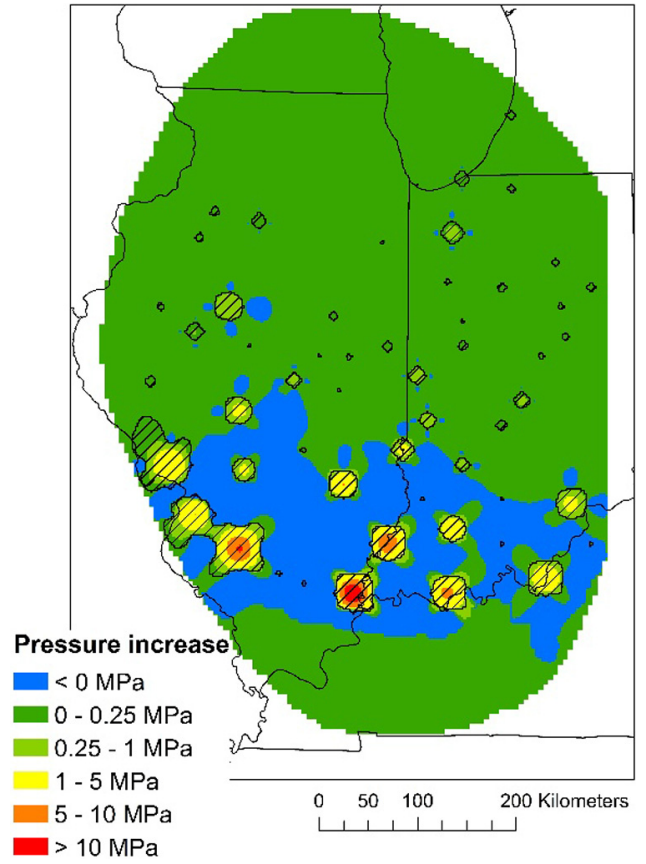

Fig. 8. Pressure increase and AoR in the injection formation for the on-site scenario after 50 years of continuous injection with $100 \%$ brine production only at sites where the AoR-plume ratio is greater than one (i.e., sites where critical pressure-based AoR is larger than the plume-based AoR).

merge and the non-associated AoR in the northern part to expand. Details of the AoR characteristics are given in Table 3.

The volume of brine produced in the scenarios described above is very large. For instance, the high injection-rate sites in the southwest of the domain each produce approximately $38,500 \mathrm{~m}^{3}$ brine per day, leading to a brine disposal issue. Due to the high salinity of the Mount Simon Sandstone brine (Zhou et al., 2010) it is unlikely useable as process water in the associated industrial facility and therefore needs to be disposed of. It is common practice in the oil and gas industry to re-inject water that is co-produced with hydrocarbon back into the subsurface, either into the production formation or into other overlying formations. For the case of $\mathrm{CO}_{2}$ storage, the goal of brine production is to reduce the pressure in the injection formation, and therefore injecting brine into the injection formation would defeat that purpose. In this study brine is injected into the upper part of the Mount Simon Sandstone (Upper Mount Simon) or into the aquifer that lies directly above the Eau Claire (Lower Knox Group). As current technology is not able to desalinate brine above $80,000 \mathrm{mg} / \mathrm{L}$ (Bourcier et al., 2011), all the brine is re-injected into the subsurface. For the brine re-injection scenarios, brine management is only conducted at sites where the AoR-plume ratio is greater than one. In addition to injecting the full brine volume, scenarios injecting only $25 \%$ of the produced brine volume are simulated to model injection of concentrated effluent from future desalinization technologies.

Re-injection of the produced brine into the Upper Mount Simon leads to relatively low brine injection pressures due to high permeability of the formation. However, the pressure response and resulting AoRs in the Mount Simon Arkosic Unit are the same as for the scenario without brine production, with the total size of the AoRs of about $198,000 \mathrm{~km}^{2}$, compared to $18,000 \mathrm{~km}^{2}$ for the case without brine re-injection. The pressure reduction from brine production in the Mount Simon Arkosic Unit is canceled by the pressure increase from brine injection into the Upper Mount Simon, because the zones of lower permeability within the Mount Simon do not have sufficiently low permeability to hydraulically isolate 
Table 3

AoRs for scenarios with brine production only at specific sites. The percentage values in the fourth column are AoR size relative to the case of no brine production.

\begin{tabular}{|c|c|c|c|c|}
\hline Scenario & $\begin{array}{l}\text { Number of sites with brine } \\
\text { production }\end{array}$ & Brine produced $\left[10^{6} \mathrm{~m}^{3} / \mathrm{yr}\right]$ & Combined AoR $\left[1000 \mathrm{~km}^{2}\right]$ & AoR-plume ratio \\
\hline No brine production & 0 & 0 & $198.1(100 \%)$ & 15.85 \\
\hline All sites & 54 & $277(100.0 \%)$ & $17.9(9.0 \%)$ & 1.41 \\
\hline AoR-plume ratio >1 & 23 & $266(96.2 \%)$ & $18.3(9.2 \%)$ & 1.44 \\
\hline AoR-plume ratio >2 & 20 & $256(92.4 \%)$ & $19.5(9.8 \%)$ & 1.53 \\
\hline AoR-plume ratio $>5$ & 17 & $239(86.2 \%)$ & $40.2(20.3 \%)$ & 3.16 \\
\hline AoR-plume ratio >10 & 10 & $133(47.9 \%)$ & $85.4(43.1 \%)$ & 6.79 \\
\hline
\end{tabular}

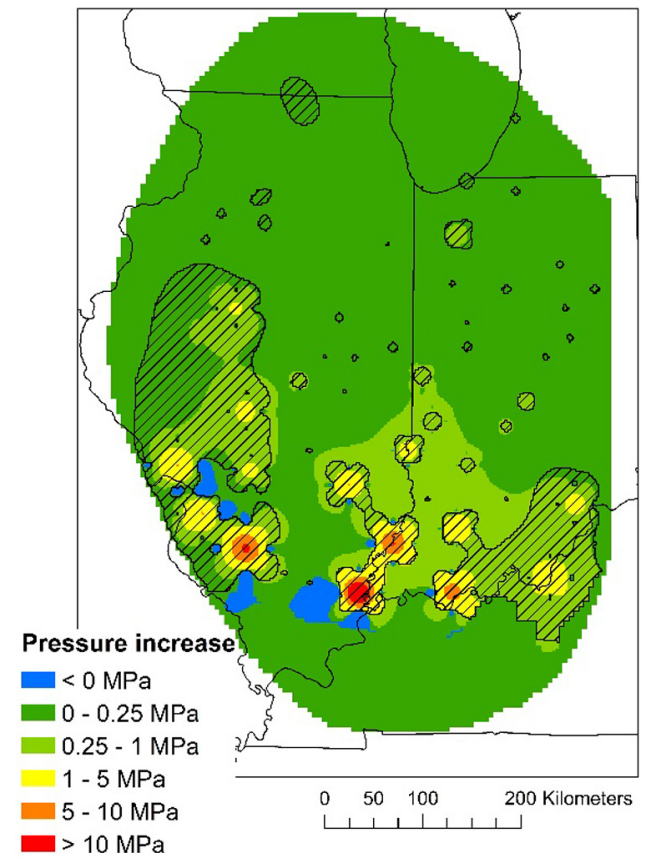

Fig. 9. Pressure response and AoRs in the Mount Simon Arkosic Unit for $25 \%$ brine re-injection into the Upper Mount Simon.

the Mount Simon Arkosic Unit and Upper Mount Simon from each other. Reducing the brine injection volume to $25 \%$ of the production rate reduces the combined size of the AoRs to about $62,000 \mathrm{~km}^{2}$ (Fig. 9), with AoR clusters forming in the southern part of the basin and AoRs unassociated with GCS sites forming in the north. Also, drilling wells for brine re-injection through the Eau Claire Formation increases the number of penetrations through the caprock, increasing the risk of post-injection $\mathrm{CO}_{2}$ leakage.

In the second set of scenarios, brine is re-injected into the Lower Knox Group, the first aquifer above the caprock (Eau Claire). The Eau Claire isolates the $\mathrm{CO}_{2}$ injection formation from the brine injection formation for much of the basin leading to a pressure response and AoRs similar to the base case (Fig. 10a). However, the Eau Claire is relatively thin in the southwestern part of the basin $(<100 \mathrm{~m})$, allowing for communication between the Mount Simon and the Lower Knox Group. Therefore, the pressure in the Mount Simon Arkosic Unit is elevated in that window, creating a cluster of overlapping AoRs. The overall AoR covers an area of about $49,000 \mathrm{~km}^{2}$. Injecting brine at $25 \%$ of the production rate leads to AoRs very similar to those of the case without re-injection (Fig. 10b), with a total AoR of $21,000 \mathrm{~km}^{2}$. However, the pressure interference from the brine re-injection is strong enough to create a small unassociated AoR in the northern part of the domain. The pressure response to brine re-injection into the Lower Knox Group is characterized by high peaks at the injection wells, but with a relatively small footprint. This pressure response is due to relatively low permeability of the Lower Knox Group in the vicinity of the GCS sites $(<10 \mathrm{mD})$.
With simulated brine injection pressures reaching above $50 \mathrm{MPa}$ for some of the wells in the southern part of the basin, fracturing of the formation should be expected.

\subsection{Regional injection center scenario}

In the regional center scenario $\mathrm{CO}_{2}$ is injected at an injection field consisting of 42 injection sites located in the center of the Illinois Basin. By moving the injection sites to locations with more favorable injection characteristics (e.g., higher thickness and permeability) the pressure response is expected to decrease, leading to a smaller area where the critical pressure is exceeded, and thus a potentially smaller AoR, as wells as lower pressure increases at the injection wells. For a case without pressure management the total AoR covers approximately $134,000 \mathrm{~km}^{2}$ (Fig. 11a), 30\% less than for the on-site scenario without pressure management. A large portion of the AoR is in the northern part of the basin where critical pressure is comparatively low. The results also show that the pressure response close to the injection wells is much lower than for the on-site scenario, due to lower injection rates and more favorable injection conditions. The $\mathrm{CO}_{2}$ plumes for the regional center scenario are much smaller, with a maximum plume diameter of about $16 \mathrm{~km}$ (Fig. 11b) compared to $42 \mathrm{~km}$ for the on-site scenario. The plumes are smaller, because of smaller maximum injection rates ( $5 \mathrm{Mt} / \mathrm{yr}$ vs $20 \mathrm{Mt} / \mathrm{yr}$ ) and larger formation thickness at the injection sites. There are some intersections between $\mathrm{CO}_{2}$ plumes, but that would be acceptable - and even desirable - if the entire injection filed were operated by a single entity. The combined $\mathrm{CO}_{2}$ plume footprint has an area of about $7500 \mathrm{~km}^{2}$, about $40 \%$ less than for the on-site scenario. The overall AoR-plume ratio for the regional center scenario without pressure management is 18.5 , suggesting a strong potential for AoR reduction through pressure management. Also, due to the more favorable injection conditions and lower injection rates, fractional pressure increases at the injection wells are around 0.27 ; well below the 0.65 limit. Therefore, injection pressure is not a constraint in the regional center scenario.

For the case of volume-equivalent brine production, the AoR is drastically reduced to $7600 \mathrm{~km}^{2}$ (Fig. 12); a reduction of $96 \%$ compared to the on-site scenario without pressure management. The AoRs are essentially reduced to the $\mathrm{CO}_{2}$ plume footprints, with an AoR-plume ratio of 1.01 . Also, the peak pressure increases are reduced to less than $1 \mathrm{MPa}$. Reducing the brine production rates to $75 \%$ of the injection volume grows the AoR beyond the confines of the injection field to an area of about $49,000 \mathrm{~km}^{2}$, and an AoR not associated with the GCS sites appears in the northern part of the domain.

In an additional scenario brine is only produced from the wells that surround the injection field (i.e., the production wells within the injection field are removed). While the number of production wells is reduced from 56 to 26 , the overall brine production rate remains the same as for the case where all production wells are active. For volume-equivalent brine production, the AoR has an area of about $10,000 \mathrm{~km}^{2}$. While this is larger than for the case with internal production wells, the AoR is still contained within the injection well field. Reducing the production rate to $75 \%$ of the 


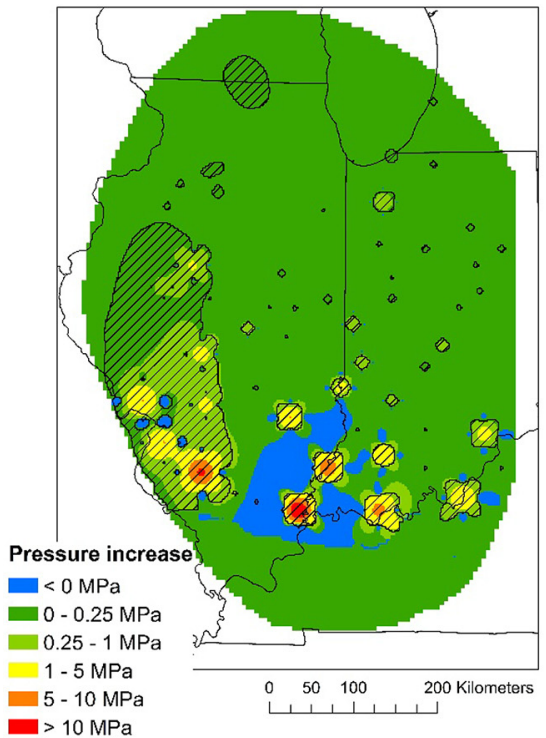

a) $100 \%$ brine re-injection

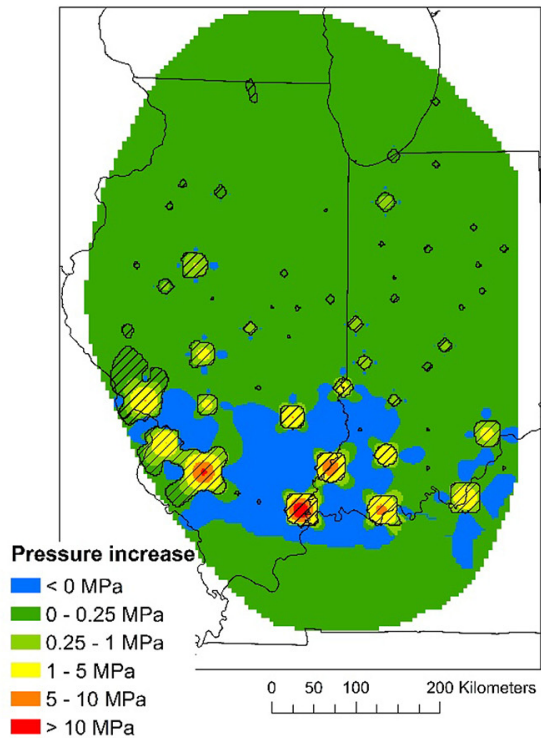

b) $25 \%$ brine re-injection

Fig. 10. Pressure response and AoRs in the Mount Simon Arkosic Unit for (a) $100 \%$ and (b) $25 \%$ brine injection into the Lower Knox Group.
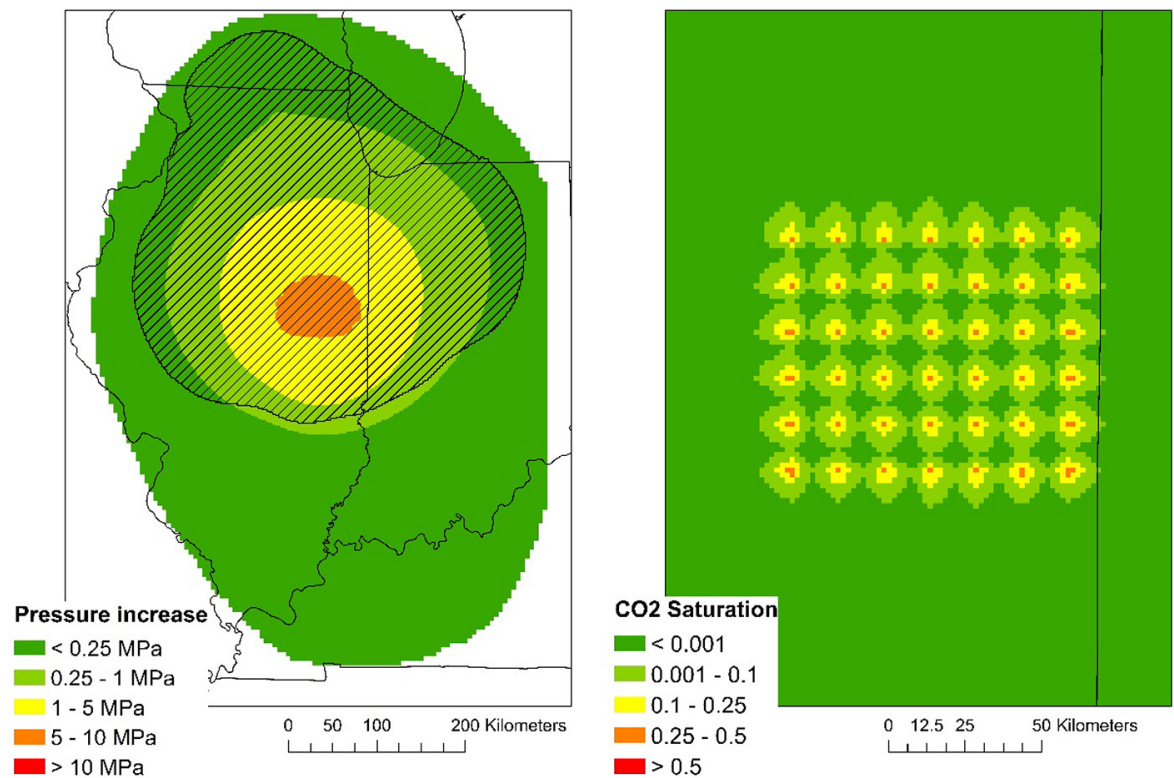

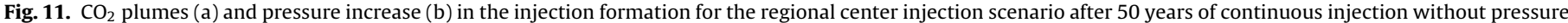
management.

injected volume increase the size of the AoR to about $32,000 \mathrm{~km}^{2}$, less than for the case with internal production wells.

\section{Discussion}

The results presented in this study show that effective pressure management strategies require removing about the same volume of brine as $\mathrm{CO}_{2}$ is injected. Globally reducing the brine production rates to $75 \%$ of $\mathrm{CO}_{2}$ injection rates leads to an increase of the AoR size by a factor of 3 for the on-site scenario and a factor of 6 for the regional center scenario. These basin-scale results confirm earlier site-scale results (Bandilla et al., 2012a; Buscheck et al., 2011) that a volume-equivalent exchange of brine and $\mathrm{CO}_{2}$ is effective for brine management. The results also suggest that it is more important to satisfy the volume balance locally than globally. Removing pressure management at GCS sites where the critical pressure-defined AoR is no more than twice the size of the saturation-defined AoR reduced the volume of brine produced basin-wide by about $8 \%$ compared to case with production at all GCS sites, while maintaining the volume balance at the sites where pressure management is necessary. The total size of the AoR increased by only about $1500 \mathrm{~km}^{2}$ for the case where there is no pressure management at the smaller GCS sites.

In this study two injection scenarios are compared: one where $\mathrm{CO}_{2}$ is injected at sites of the $\mathrm{CO}_{2}$ sources and one where $\mathrm{CO}_{2}$ is transported to a regional injection center for injection. The results show that even without brine production the total AoR for the regional center scenario is about $30 \%$ smaller than for the on-site scenario and that fractional pressure increases at the injection wells are below the maximum value of 0.65 for the regional center scenario, compared to four sites exceeding the maximum fractional 


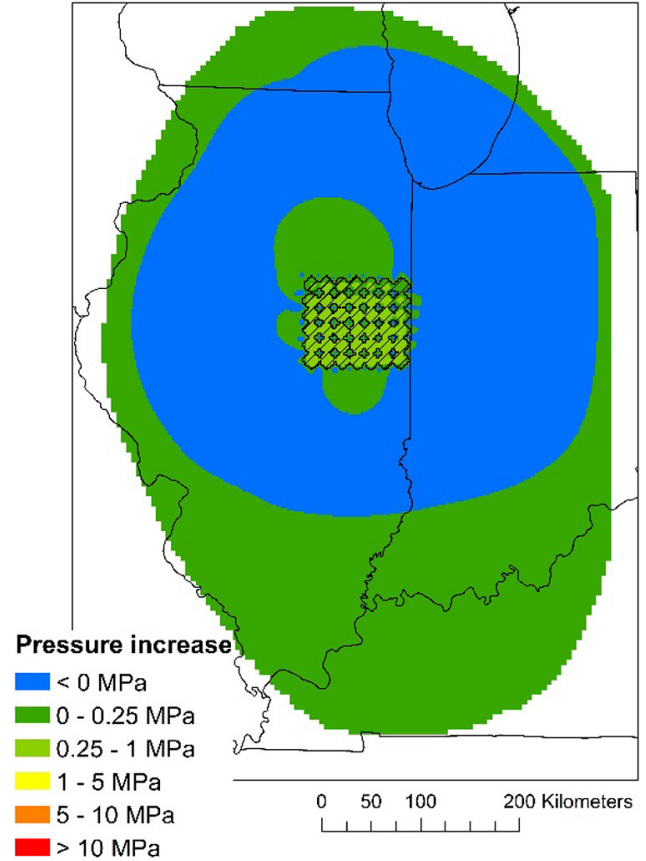

Fig. 12. Pressure increase and $A o R$ in the injection formation for the regional center scenario after 50 years of continuous injection with $100 \%$ brine production.

pressure increase for the on-site scenario. The pressure response is lower, due to more favorable injection conditions and due to smaller per-well injection rates for the regional center scenario. This is in contrast to several of the GCS sites in the on-site scenario, where the thickness and/or permeability are low, but the injection rates are high. For example, the four sites where injection pressures are above $10 \mathrm{MPa}$ for the on-site scenario without pressure management have injection rates of 7.3, 11.5, 16.5 and $21.1 \mathrm{Mt} / \mathrm{yr}$ and brine transmissivities (thickness * hydraulic conductivity) of $3.0 \times 10^{-5}, 9.4 \times 10^{-5}, 1.4 \times 10^{-4}$ and $2.3 \times 10^{-4} \mathrm{~m}^{2} / \mathrm{s}$. All four of these wells are located in southern part of the basin. The pressure increase at a GCS site with a comparable injection rate but more favorable injection conditions (11.2 Mt/yr, $2.3 \times 10^{-3} \mathrm{~m}^{2} / \mathrm{s}$ ) located in the northern part of the domain is much lower (below $1 \mathrm{MPa}$ ). However, the critical pressure in the northern part of the basin is lower than in the south, leading to a larger AoR for the GCS sites in the north (Fig. 4). For comparison, the transmissivities at injection wells for the regional center scenario range from $9.1 \times 10^{-4}$ to $2.0 \times 10^{-3} \mathrm{~m}^{2} / \mathrm{s}$ and the per-well injection rate is $5 \mathrm{Mt} / \mathrm{yr}$, leading to maximum pressure increases below $10 \mathrm{MPa}$ for the scenario without pressure management. These results suggest that, from the standpoints of minimizing AoRs and maximizing injection rates, using a regional injection center located in the sweet-spot of transmissivity, critical pressure increase and maximum allowable fractional pressure increase should be preferred over on-site injection. An additional benefit of using an injection center is that overlapping AoRs would not be problematic as a single entity would be liable for all injection sites. Overlapping pressure responses would even be beneficial, as this would lead to a smaller overall AoR. A closely-spaced injection field would also increase the storage efficiency, as the $\mathrm{CO}_{2}$ plumes would be more compact due to the quasi no-flow boundary conditions imposed by neighboring injection wells. However, transporting $\mathrm{CO}_{2}$ to the regional center comes with the cost of building and operating pipelines, which needs to be weighed against the cost of larger AoRs (e.g., characterization and abandoned well mitigation).

Based on the results presented here, injectivity does not seem to be a limiting factor for GCS operations in the Illinois Basin, as long as especially unfavorable areas are avoided. For the on-site scenario four wells located along the southwestern edge of the basin exceed the maximum allowable fractional pressure increase. All four sites are injecting into a relative thin part of the Arkosic Unit of the Mount Simon Sandstone (Fig. 2), with thickness values ranging from 12 to $29 \mathrm{~m}$. Reducing the injection rates of the four sites by between $25 \%$ and $50 \%$ is sufficient to reduce the pressure increase at the injection wells below the maximum allowable value; an overall reduction of injection rate by $18.6 \mathrm{Mt} / \mathrm{yr}$ or $9 \%$ of the full injection rate. Volume equivalent brine production has limited impact on the pressure at the four injection wells that exceed the fractional pressure increase limit, with only one site dropping below the limit. Increasing the production rates at the three remaining sites to twice the injection rate, leads to a sufficient pressure reduction at one more site. However, $\mathrm{CO}_{2}$ breakthrough occurs at two of the production wells. Choice of injection location appears to be the better strategy to control pressure at the injection wells, as the maximum fractional pressure increase is not exceeded for the regional center scenario. Zhou et al. (2010) also found that industrial-scale injection in the central section of the basin was not limited by the pressure increase at the injection wells.

While pressure management through brine production is an effective approach to reduce the size of an AoR, disposal can be a serious problem due to the large volumes of produced brine. The results from this study show that brine re-injection should only occur in a formation that is separated from the $\mathrm{CO}_{2}$ injection formation by a formation with sufficiently low permeability, to avoid canceling out the pressure reduction from the brine production wells. While brine disposal through re-injection into the subsurface has a long history in the oil and gas industry, this practice has recently been linked to induced seismicity in Oklahoma (Keranen et al., 2014). Brine injection volumes are expected to be at least as high - if not higher - than in the oil and gas industry, and therefore, GCS operators will have to be careful when choosing re-injection formations. For instance, a study by Zhang et al. (2013) based on $\mathrm{CO}_{2}$ injection, shows that injection should not occur directly above the crystalline basement. Also, re-injection formations should have sufficient injectivity and depth, so that the brine can be injected at the necessary rates without fracturing the formation and brine leakage to potential USDWs is minimized. In the oil and gas industry brine re-injection into the formation from which hydrocarbons are being produced is sometimes used as pressure support in mature fields, however this approach would be counter-productive for the case of pressure management at GCS sites.

As expected, reducing the brine injection volume has a strong impact on the pressure response in the injection formation. For instance, re-injecting only $25 \%$ of the produced brine into the overlying Lower Knox Group formation leads to a pressure response in the injection formation that is very similar to the case without re-injection, while re-injecting the full volume leads to a significant increase in the overall AoR (Fig. 10). Re-injection volumes may be reduced if the produced brine is amenable to desalination, so that the injected brine would be the concentrated effluent resulting from desalination. While the brines of the Mount Simon Sandstone are likely too saline for desalination, less saline brine - with or without desalination - may be used in power plants as cooling or process water. Based on ranges of water withdrawal of coal-fired power plants (Feeley et al., 2008), desalinated brine could provide from a few percent to over half of water withdrawal rates (assuming $100 \%$ carbon capture and volume-equivalent production), although withdrawal rates may need to be increased due to the potentially high temperature of the produced brine.

The area of relatively low thickness of the Eau Claire shale - the caprock of the injection formation - is an interesting feature, as it allows for modest pressure communication between the Mount Simon Sandstone and the Knox Group. Brine leakage through the 
Eau Claire acts as a pressure relief for the Mount Simon Sandstone, which benefits a GCS operation by lowering the injection pressure and decreasing the size of the pressure defined AoR. $\mathrm{CO}_{2}$ is not expected to leak through the thinner areas of the Eau Claire, due to capillary exclusion. While the pressure communication decreases the pressure in the injection formation, it also increases the pressure in the Mount Simon Sandstone for the case of brine injection into the Lower Knox Group.

\section{Conclusion}

In this study the impact of active pressure management on injection rates and AoR sizes of GCS operations at industrial-scale deployment is examined. The Illinois Basin, US is used as a hypothetical test case, with approximately $207 \mathrm{Mt}$ of $\mathrm{CO}_{2}$ being injected per year for a duration of 50 years. Two scenarios are considered: one where $\mathrm{CO}_{2}$ is injected at the locations of 54 large $\mathrm{CO}_{2}$ sources (on-site), and the other where $\mathrm{CO}_{2}$ is injected in a central well field comprised of 42 closely spaced injection wells (regional center). The model consists of eleven layers; six aquifers separated by five aquitards. The Arkosic Unit, the lowest layer of the Mount Simon Sandstone, is the injection target, while the Ordovician Carbonate aquifer, at the top of the sedimentary stack, is considered the USDW.

Modeling results show that pressure management will need to be part of geologic carbon storage operations under current regulations of delineation of the AoR in the US. The injectioninduced pressure increase is high enough that the critical pressure is exceeded over an area of $198,000 \mathrm{~km}^{2}$, or about $65 \%$ of the domain. Such a large AoR is impractical, because of the high cost of characterizing the subsurface over such a large area, and because overlapping AoRs make the boundaries of responsibility of individual GCS operations unclear. Producing brine from the injection formation significantly reduces the pressure response and therefore the AoR. When the same volume of brine is produced as $\mathrm{CO}_{2}$ being injected, and production occurs at each of the 54 injection sites, the AoRs are decoupled and the combined size of the individual AoRs decreases to $18,000 \mathrm{~km}^{2}$. Reduction of the brine production volume to $75 \%$ of the injected $\mathrm{CO}_{2}$ volume leads to an increase in the size of the AoRs to about $58,000 \mathrm{~km}^{2}$, suggesting that a one-to-one volume exchange of $\mathrm{CO}_{2}$ and brine is appropriate for effective pressure management. The need for pressure management to reduce the size of AoRs should be reevaluated if the current delineation guidelines are modified to take a risk-based approach (Birkholzer et al., 2014).

Restrictions on injection rates due to exceeding the fractional pressure increase limit of 0.65 does not seem to be an issue for injections into the Arkosic Unit of the Mount Simon Sandstone. Injections at only four of 54 sites of the on-site scenario exceed the fractional pressure increase limit and all of the injections for the regional center scenario are well below the limit. Pressure increases at the four sites can be lowered below the limit by decreasing injection rates at those sites by $25-50 \%$, leading to a reduction in basin-wide injection rate of about $9 \%$. Brine production does not seem to be a good strategy for reducing the pressure at the injection wells here, as only one of the four sites is reduced below the limit for volume equivalent brine production. Higher brine production rates can reduce the pressure at the three remaining wells below the fractional pressure increase limit, but at the cost of $\mathrm{CO}_{2}$ breakthrough at the brine production wells.

Pressure management may not be necessary at all storage operations. For the cases studied here, at sites with an annual injection rate of less than $1 \mathrm{Mt}$ of $\mathrm{CO}_{2}$, the operation's AoR was defined mainly by the $\mathrm{CO}_{2}$ plume and not the pressure increase, meaning that pressure management would not be able to decrease the size of the
AoR. If pressure management is only conducted at sites where the area of critical pressure exceedance is at least twice as big as the footprint of the $\mathrm{CO}_{2}$ plume, the combined size of all AoRs grows by less than $10 \%$ to about $19,200 \mathrm{~km}^{2}$, while eliminating pressure management operations at 34 sites. While the number of sites with pressure management is greatly reduced, the overall volume of produced brine only decreases by about $7.5 \%$, because the majority of $\mathrm{CO}_{2}$ is injected at a small number of sites with high injection rates.

With regards to the location of the storage operations, the modeling results show that the size of the AoR can be reduced by $30 \%$ and injection rates are not limited by pressure constraints if the storage sites are chosen based on the storage formation properties, instead of based on the location of large $\mathrm{CO}_{2}$ sources. When the injection wells are grouped in a closely-spaced well field and brine is produced from within the well field, the pressure increase exceeds critical pressure only very close to injection wells. Therefore, the AoRs are defined by the $\mathrm{CO}_{2}$ plume size only and the AoRs are completely contained within the well field. Also, fractional pressure increases are below the regulatory limit for all injection wells. Due to the close spacing of the injection wells $(15 \mathrm{~km})$ the $\mathrm{CO}_{2}$ plumes merge, leading to a more efficient use of the pore space.

In conclusion, the results presented here show that under the current regulations pressure management will be important if GCS is to be deployed at an industrial scale. The results also show that a volume of brine equivalent to the volume of injected $\mathrm{CO}_{2}$ needs to be produced to significantly reduce the size of the AoRs and separate the individual AoRs. However, the necessity of pressure management will be site-specific, as sites with smaller injection rates ( $<1 \mathrm{Mt} / \mathrm{yr}$ ) and/or favorable storage formation properties may not require pressure management. Also, the benefits of smaller AoRs and higher injection rates, need to be weighed against the cost of brine production and disposal as well as the risk of additional artificial penetrations of the caprock. Lastly, injection in a closely-spaced well field located in an area with favorable storage properties reduces the pressure response and the extent of the $\mathrm{CO}_{2}$ plumes when compared to injection at source locations.

\section{Acknowledgments}

This material is based upon work supported by the Carbon Mitigation Initiative at Princeton University and by the U.S. Department of Energy (DOE) National Energy Technology Laboratory (NETL) under Grant Number FE009563. This project is managed and administered by Princeton University and funded by DOE/NETL and cost-sharing partners. Neither the United States Government nor any agency thereof, nor any of their employees, makes any warranty, express or implied, or assumes any legal liability or responsibility for the accuracy, completeness, or usefulness of any information, apparatus, product, or process disclosed, or represents that its use would not infringe privately owned rights. Reference herein to any specific commercial product, process, or service by trade name, trademark, manufacturer, or otherwise does not necessarily constitute or imply its endorsement, recommendation, or favoring by the United States Government or any agency thereof. The views and opinions of authors expressed herein do not necessarily state or reflect those of the United States Government or any agency thereof.

\section{References}

Athy, L.F., 1930. Density, porosity, and compaction of sedimentary rocks. AAPG Bull. 14 (1), 1-24.

Bandilla, K., Elliot, T.R., Celia, M.A., 2012a. Comparison of brine production scenarios for geologic carbon sequestration operations. Paper presented at the Carbon Management Technology Conference. 
Bandilla, K.W., Celia, M.A., Birkholzer, J.T., Cihan, A., Leister, E.C., 2015. Multiphase modeling of geologic carbon sequestration in saline aquifers. Groundwater 53 (3), 362-377, http://dx.doi.org/10.1111/gwat.12315.

Bandilla, K.W., Celia, M.A., Elliot, T.R., Person, M., Ellett, K.M., Rupp, J.A., Zhang, Y., 2012b. Modeling carbon sequestration in the Illinois Basin using a vertically-integrated approach. Comput. Visual. Sci. 15 (1), 39-51, http://dx. doi.org/10.1007/s00791-013-0195-2.

Bandilla, K.W., Kraemer, S.R., Birkholzer, J.T., 2012c. Using semi-analytic solutions to approximate the area of potential impact for carbon dioxide injection. Int. J. Greenh. Gas Control 8, 196-204, http://dx.doi.org/10.1016/j.ijggc.2012.02.009.

Battistelli, A., Calore, C., Pruess, K., 1997. The simulator TOUGH2/EWASG fo modelling geothermal reservoirs with brines and non-condensible gas. Geothermics 26 (4), 437-464

Birkholzer, J., Cihan, A., Bandilla, K., 2014. A tiered area-of-review framework for geologic carbon sequestration. Greenh. Gases-Sci. Technol. 4 (1), 20-35.

Birkholzer, J.T., Cihan, A., Zhou, Q.L., 2012. Impact-driven pressure management via targeted brine extraction-conceptual studies of $\mathrm{CO}_{2}$ storage in saline formations. Int. J. Greenh. Gas Control 7, 168-180, http://dx.doi.org/10.1016/j. ijggc.2012.01.001.

Bourcier, W.L., Wolery, T.J., Wolfe, T., Haussmann, C., Buscheck, T.A., Aines, R.D., 2011. A preliminary cost and engineering estimate for desalinating produced formation water associated with carbon dioxide capture and storage. Int. J. Greenh. Gas Control 5 (5), 1319-1328, http://dx.doi.org/10.1016/j.ijggc.2011 06.001.

Buscheck, T.A., Bielicki, J.M., Chen, M.J., Sun, Y.W., Hao, Y., Edmunds, T.A., Randolph, J.B., 2014. Integrating $\mathrm{CO}_{2}$ storage with geothermal resources for dispatchable renewable electricity. Energy Proc. 63, 7619-7630, http://dx.doi.org/10.1016/j egypro.2014.11.796.

Buscheck, T.A., Elliot, T.R., Celia, M.A., Chen, M.J., Sun, Y.W., Hao, Y., Aines, R.D. 2013. Integrated geothermal- $\mathrm{CO}_{2}$ reservoir systems: reducing carbon intensity through sustainable energy production and secure $\mathrm{CO}_{2}$ storage. Energy Proc 37, 6587-6594, http://dx.doi.org/10.1016/j.egypro.2013.06.591.

Buscheck, T.A., Sun, Y.W., Chen, M.J., Hao, Y., Wolery, T.J., Bourcier, W.L., Aines, R.D., 2012. Active $\mathrm{CO}_{2}$ reservoir management for carbon storage: analysis of operational strategies to relieve pressure buildup and improve injectivity. Int. J. Greenh. Gas Control 6, 230-245, http://dx.doi.org/10.1016/j.ijggc.2011.11.007.

Buscheck, T.A., Sun, Y.W., Hao, Y., Wolery, T.J., Bourcier, W., Tompson, A.F.B., Aines R.D., 2011. Combining brine extraction, desalination, and residual-brine reinjection with $\mathrm{CO}_{2}$ storage in saline formations: implications for pressure management, capacity, and risk mitigation. 10th International Conference on Greenhouse Gas Control Technologies vol. 4, 4283-4290, http://dx.doi.org/10 1016/j.egypro.2011.02.378.

Buscheck, T.A., White, J.A., Carroll, S.A., Bielicki, J.M., Aines, R.D., 2016. Managing geologic $\mathrm{CO}_{2}$ storage with pre-injection brine production: a strategy evaluated with a model of $\mathrm{CO}_{2}$ injection at Snøhvit. Energy Environ. Sci. 9 (4), 1504-1512.

Cihan, A., Birkholzer, J., Bianchi, M., 2014. Targeted pressure management during $\mathrm{CO}_{2}$ sequestration: optimization of well placement and brine extraction. Energy Proc. 63, 5325-5332, http://dx.doi.org/10.1016/j.egypro.2014.11.564.

Cook, P.J., 2009. Demonstration and deployment of carbon dioxide capture and storage in Australia. Greenh. Gas Control Technol. 1 (1), 3859-3866, http://dx. doi.org/10.1016/j.egypro.2009.02.188.

Court, B., Bandilla, K.W., Celia, M.A., Buscheck, T.A., Nordbotten, J.M., Dobossy, M., Janzen, A., 2012a. Initial evaluation of advantageous synergies associated with simultaneous brine production and $\mathrm{CO}_{2}$ geological sequestration. Int. J. Greenh. Gas Control 8, 90-100, http://dx.doi.org/10.1016/j.ijggc.2011.12.009.

Court, B., Bandilla, K.W., Celia, M.A., Janzen, A., Dobossy, M., Nordbotten, J.M., 2012b. Applicability of vertical-equilibrium and sharp-interface assumptions in $\mathrm{CO}_{2}$ sequestration modeling. Int. J. Greenh. Gas Control 10, 134-147, http:/| dx.doi.org/10.1016/j.ijggc.2012.04.015.

Court, B., Celia, M.A., Nordbotten, J.M., Elliot, T.R., 2011. Active and integrated management of water resources throughout $\mathrm{CO}_{2}$ capture and sequestration operations. 10th International Conference on Greenhouse Gas Control Technologies vol. 4, 4221-4229, http://dx.doi.org/10.1016/j.egypro.2011.02. 370.

Deichmann, N., Giardini, D., 2009. Earthquakes induced by the stimulation of an enhanced geothermal system below basel (Switzerland). Seismol. Res. Lett. 80 (5), 784-798, http://dx.doi.org/10.1785/gssrl.80.5.784.

EPA, U. (2010). Federal Requirements Under the Underground Injection Control (UIC) Program for Carbon Dioxide $\left(\mathrm{CO}_{2}\right)$ Geologic Sequestration (GS) Wells, Final Rule. In: U. S. E. P. A. (EPA) (Ed.), (Vol. 40 CFR Parts 124, 144, 145, et al.). Federal Register.
Feeley, T.J., Skone, T.J., Stlegel, G.J., McNemar, A., Nemeth, M., Schimmoller, B. Manfredo, L., 2008. Water: a critical resource in the thermoelectric power industry. Energy 33 (1), 1-11, http://dx.doi.org/10.1016/j.energy.2007.08.007.

Finley, R.J., 2014. An overview of the Illinois Basin - Decatur Project. Greenh. Gases-Sci. Technol. 4 (5), 571-579, http://dx.doi.org/10.1002/ghg.1433.

Johnson, J.W., Nitao, J.J., Morris, J.P., 2005. Reactive transport modeling of cap-rock integrity during natural and engineered $\mathrm{CO}_{2}$ storage. Carbon Dioxide Capture for Storage in Deep Geologic Formations - Results from the $\mathrm{CO}_{2}$ Capture Project, vols. 1 and 2., pp. 787-813.

Keranen, K.M., Weingarten, M., Abers, G.A., Bekins, B.A., Ge, S., 2014. Sharp increase in central Oklahoma seismicity since 2008 induced by massive wastewater injection. Science 345 (6195), 448-451, http://dx.doi.org/10.1126/science. 1255802.

Kintisch, E., 2015. After Paris: the rocky road ahead. Science 350 (6264), 1018-1019.

Lindeberg, E., Vuillaume, J.F., Ghaderi, A., 2009. Determination of the $\mathrm{CO}_{2}$ storage capacity of the Utsira formation. Energy Proc. 1 (1), 2777-2784, http://dx.doi org/10.1016/j.egypro.2009.02.049.

Mehnert, E., Damico, J., Frailey, S., Leetaru, H., Okwen, R., Storsved, B., Valocchi, A. 2014. Basin-scale modeling for $\mathrm{CO}_{2}$ sequestration in the basal sandstone reservoir of the Illinois Basin-Improving the geologic model. Energy Proc. 63, 2949-2960, http://dx.doi.org/10.1016/j.egypro.2014.11.317.

Metz, B., Davidson, O., De Coninck, H., Loos, M., Meyer, L., 2005. International Panel on Climate Change Special Report on Carbon Dioxide Capture and Storage. Cambridge University Press, Cambridge.

Michael, K., Bunch, M., Varma, S., 2013. Simulation of the cumulative impacts of $\mathrm{CO}_{2}$ geological storage and petroleum production on aquifer pressures in the offshore Gippsland Basin. Int. J. Greenh. Gas Control 19, 310-321.

Michael, K., Golab, A., Shulakova, V., Ennis-King, J., Allinson, G., Sharma, S., Aiken, T., 2010. Geological storage of $\mathrm{CO}_{2}$ in saline aquifers - a review of the experience from existing storage operations. Int. J. Greenh. Gas Control 4 (4), 659-667.

NETL, 2015. Carbon Storage Atlas V. National Energy Technology Laboratory.

Nordbotten, J.M., Celia, M.A., 2006. Similarity solutions for fluid injection into confined aquifers. J. Fluid Mech. 561, 307-327.

Nordbotten, J.M., Celia, M.A., 2012. Geological Storage of $\mathrm{CO}_{2}$ : Modeling Approaches for Large-scale Simulation. Wiley, Hoboken, NJ.

Nordbotten, J.M., Dahle, H.K., 2011. Impact of the capillary fringe in vertically integrated models for $\mathrm{CO}_{2}$ storage. Water Resour. Res. 47, W02537, http://dx. doi.org/10.1029/2009wr008958.

Oldenburg, C.M., 2012. The risk of induced seismicity: is cap-rock integrity on shaky ground? Greenh. Gases-Sci. Technol. 2 (4), 217-218, http://dx.doi.org/ 10.1002/ghg.1299.

Pacala, S., Socolow, R., 2004. Stabilization wedges: solving the climate problem for the next 50 years with current technologies. Science 305 (5686), 968-972, http://dx.doi.org/10.1126/science.1100103.

Person, M., Banerjee, A., Rupp, J., Medina, C., Lichtner, P., Gable, C., Bense, V., 2010. Assessment of basin-scale hydrologic impacts of $\mathrm{CO}_{2}$ sequestration, Illinois basin. Int. J. Greenh. Gas Control 4 (5), 840-854, http://dx.doi.org/10.1016/j. ijggc.2010.04.004.

Rutqvist, J., 2012. The geomechanics of $\mathrm{CO}_{2}$ storage in deep sedimentary formations. Geotech. Geol. Eng. 30 (3), 525-551, http://dx.doi.org/10.1007/ s10706-011-9491-0.

Yortsos, Y.C., Satik, C., Bacri, J.C., Salin, D., 1993. Large-scale percolation theory of drainage. Transp. Porous Media 10 (2), 171-195, http://dx.doi.org/10.1007/ Bf00617007.

Zhang, Y.P., Person, M., Rupp, J., Ellett, K., Celia, M.A., Gable, C.W., Elliot, T., 2013. Hydrogeologic controls on induced seismicity in crystalline basement rocks due to fluid injection into basal reservoirs. Ground Water 51 (4), 525-538, http://dx.doi.org/10.1111/gwat.12071.

Zhou, Q.L., Birkholzer, J.T., Mehnert, E. Lin, Y.F., Zhang, K., 2010. Modeling basinand plume-scale processes of $\mathrm{CO}_{2}$ storage for full-scale deployment. Ground Water 48 (4), 494-514, http://dx.doi.org/10.1111/j.1745-6584.2009.00657.x.

Zoback, M.D., Gorelick, S.M., 2012. Earthquake triggering and large-scale geologic storage of carbon dioxide. Proc. Natl. Acad. Sci. U. S. A. 109 (26), 10164-10168, http://dx.doi.org/10.1073/pnas.1202473109. 